\title{
Bending it Like Beckham: Movement, Control and Deviant Causal Chains
}

\section{MARKUS E. SCHLOSSER}

Forthcoming in Analysis

This is the author's copy that may differ from the final print version

Like all causal theories in philosophy, the causal theory of action is plagued by the problem of deviant causal chains. I have proposed a solution on the basis of the assumption that mental states and events are causally efficacious in virtue of their contents (Schlosser 2007). This solution has been questioned by Torbjörn Tännsjö (2009). First, I will reply to the objection, and then I will discuss Tännsjö’s alternative.

The most difficult cases of causal deviance share the following structure. There is an agent's mental state or event, $R$, that rationalizes the performance of an action of type $A$. $R$ causes an intermediary state, $N$, which causes a movement of type $M$. This movement would constitute or realize an instance of $A$-ing, were it not caused by $N$. Typically, $N$ is a state that appears to undermine the agent's control over the movement, such as a state of severe nervousness, and so it seems clear that the agent does not perform an action at all. But according to a causal theory, the agent performs an $A$-ing, as $M$ is both caused and rationalized by $R$. (I called this the problem of basic deviance, as it concerns the performance of basic actions.)

I argued that this problem does not arise if the theory requires that the mental antecedent must cause and explain the action in virtue of its intentional content. $R$ causes 
and rationalizes $M$, but it does not cause and explain it in virtue of its content. I have also offered a response to the following challenge.

The solution is unproblematic if there is no causal intermediary, and it appears to rule out states such as nervousness or agitation. But sometimes, perhaps even always, the causal chain that connects the mental antecedent and the action runs through numerous causal intermediaries. These intermediaries are typically not intentional or contentbearing states (think, for instance, of all the events that connect brain activity and muscle movement). Given this, the condition that basic actions must be caused and explained in virtue of content is obviously too strong.

My response was that this objection confuses levels of explanation. The causal chains that realize the mental causation of actions are highly complex chains at lower levels of explanation. But at the level of intentional explanation, we can identify only states and events such as intentions, actions, nervousness, and so on. According to Tännsjö, this 'misses the point':

The problem is not that there are always causal chains that run through nonintentional states and, in particular, the problem is not that theses chains appear at the neurophysiological level. The problem is that there are some cases where even folk psychology allows for such non-intentional parts of an action. A simple example is when I kick a ball. There are many movements of my legs that are not made in response to the content of my wish to kick the ball [...]. (2009: 470). 
I am happy to grant the first point, as I did not mean to suggest that that is the problem. The important question is whether there are any robust examples that raise a problem for my solution. There is a problem if there are examples of non-deviant causation in which the causal chain passes through an intermediary event, at the level of commonsense psychology, that lacks intentional content. Tännsjö has not identified such an event, because he has not identified any causal intermediary. In the example, he talks about the 'non-intentional parts of an action' (my emphasis). Whatever is a part of an action cannot possibly be its cause. This seems so clear to me that I am simply puzzled by the objection.

In general, this kind of challenge raises difficult questions concerning the metaphysics of action and mental causation. How are actions and events to be individuated? What is the relationship between actions and movements? Do mental states cause actions or movements? And so forth. The proponents of the challenge tend to ignore this, as they take their point to be just obvious. But a little bit more care is required.

As I see it, the mental causation of action takes place, strictly, at the level of commonsense psychology. If the action is an overt action, then there is a sense in which the mental antecedent causes a movement. But this does not mean that it causes the chain of events that leads to the movement as it is described at a lower level. The notion of movement is ambiguous. In a sense, movements belong to the level of commonsense psychology. We say that the trembling of his hands was caused by his nervousness, for instance. But movements belong also to lower levels of scientific explanation. When my intention to raise an arm causes a movement, it causes a movement in the first sense. It causes a rising of an arm, which is one coarse-grained event at the level of commonsense psychology. 
Let us return to the example. The agent kicks the ball by performing a certain type of kicking movement. This kicking move is the basic action. As an action, it has no parts (in the way in which taking the bus may be a part of travelling to Rome, for instance). At the lower level, the movement has a multitude of parts. But this is not a problem, as the intention causes the action. Of course, the parts of the movement, as they appear at the lower level, must also be initiated and guided. This is achieved by a so-called motorprogramme. This type of entity belongs to a lower level of explanation, and the guidance that is provided by the motor system is unintentional and below the level of consciousness.

Arguably, the movement has parts at the level of commonsense psychology as well, as Tännsjö suggests. But this is beside the point. The action of kicking must be performed in response to the intention. This single action is constituted by one movement. The fact that this movement has parts is irrelevant, because my view does not require that such parts must be caused by a mental antecedent in virtue of its content.

\section{An Alternative Solution?}

Tännsjö suggests that we can solve the problem of causal deviance for particular types of action, and that there is, therefore, no need for a general solution. To my mind, this dialectic seems strange, because it seems strange to say that we need a general solution. We need a solution, and a general solution is worth wanting because it is parsimonious. But if we cannot find a general solution, then we might need particular solutions.

Tännsjö begins with Davidson's climber, who intends 'to rid himself of the weight and danger of holding another man on a rope' by loosening his grip on the rope. 
This intention causes a state of nervousness, which causes the loosening of his hold (Davidson 1980: 79). According to Tännsjö, every type of action 'carries its own criteria of rightness with respect to causal chains' (471). In this case, 'it is crucial that the climber has control of the movements of his hands', and Tännsjö suggests that this type of case can be solved in accordance with my proposal (ibid.). But he thinks that other types of cases require different solutions:

With respect to other acts, such as kicking, it is not necessary that every movement of the legs of the person who kicks a ball is responsive to any wish for them to move that way; the movements should be caused by his desire, but need not be in Schlosser's sense 'responsive' to it. (ibid.)

But no proponent of the causal theory has ever suggested that 'every movement of the legs' during an action such as kicking a ball must be responsive to the agent's intentionand I certainly did not either. Moreover, it is also not necessary that 'every movement' of the climber's hands is responsive to the mental antecedent. There is, in this respect, no difference between the cases.

Then Tännsjö goes on to distinguish his kicking the ball from a professional player's 'bending it like Beckham', suggesting that they constitute two different types of cases. The professional player differs from ordinary mortals, when they kick a ball, in two important respects. First, the player has an ability to control that most of us lack. Second, the degree of control that this agent has over this type of action is less than the degree of control that we have over many of our actions. 
The first point is due to differences in talent and practice. The player has acquired the ability to bend it like Beckham in years of training, developing a natural talent. This is why this agent can reasonably form the intention to bend it like Beckham. The second point concerns the limits of control. No matter how hard our player practices, she will never gain full control over the action. This is not a special case. We all know some actions over which we have only some control. The limits of intentional control are set by the limits of the underlying causal mechanisms. If it is impossible, for an agent, to acquire a motor-programme that fully governs a movement that would constitute an $A$-ing, then this agent will not be able to gain full control over $A$-ing. Both points raise difficult questions concerning the relationships between the intentional control of action and the underlying non-intentional control of movements. But they do not require a revision of the theory at the intentional level.

Suppose that the player intends to bend it like Beckham. Presumably, this results in some adjustments in her movement that would not have occurred, had she merely intended to kick the ball. These adjustments, it seems, are made in response to the content of the intention. Of course, they do not guarantee that the player will be successful in bending it like Beckham. This is because the control mechanisms that underlie that action are much less reliable than the mechanisms that underlie an action such as kicking a ball. This is perfectly compatible with my view, which requires that the mental antecedents of action must be causally efficacious in virtue of content, not that they must causally determine the action.

One may think that there is a problem in case the attempt is unsuccessful. If the player fails, then the intention to bend it like Beckham does not cause that type of action. 
But we can assume the player will be successful in kicking the ball. What action is caused in virtue of what content?

This only highlights the fact that bending it like Beckham is not a basic action. In order to bend it like Beckham, one must perform a certain type of kicking movement. In order to do that intentionally, one must intend to perform that type of kicking. And someone who intends to perform a certain type of kicking intends to perform a kicking. Further, only basic actions must be caused in virtue of content. Non-basic actions must merely match the content of the corresponding non-basic intention (compare Schlosser 2007: 189-90, for instance). So, the player's intention to perform a certain type of kicking causes a kicking move in virtue of content. This basic action gives rise to the action of kicking the ball, but it fails to give rise to an action that matches the content of the nonbasic intention to bend it like Beckham.

There is no need for a particular solution to this type of case. My general solution works perfectly well. Furthermore, I should point out that Tännsjö has not really given us a particular solution to this case. All he says is that, intuitively, 'we have a clear enough feel for the different causal requirements with respect to just kicking a ball and bending it like Beckham' (2007: 471). But there is no indication of what these causal requirements might be, and so there is no indication of what different solutions to different cases of causal deviance might actually look like.

University of Leiden 2300 RA Leiden, The Netherlands m.schlosser@hum.leidenuniv.nl 


\section{References}

Davidson, D. 1980. Essays on Action and Events. Oxford: Oxford University Press.

Tännsjö, T. 2009. On deviant causal chains — no need for a general criterion. Analysis 69: 469-473.

Schlosser, M. 2007. Basic deviance reconsidered. Analysis 67: 186-194. 